\title{
Mortality experience among employees at a hydrometallurgical nickel refinery and fertiliser complex in Fort Saskatchewan, Alberta (1954-95)
}

\author{
R Egedahl, M Carpenter, D Lundell
}

\begin{abstract}
Objective-To study the mortality experience of workers at a hydrometallurgical nickel refinery and fertiliser complex in Fort Saskatchewan, Alberta, Canada. Methods-A total of 1649 male employees of Sherritt International who worked for at least 12 continuous months during the years 1954 to 1978 at the Fort Saskatchewan, Alberta hydrometallurgical nickel refinery and fertiliser complex were followed up for an additional 17 years. Mortality was ascertained from the Canadian mortality data base maintained by Statistics Canada and covered the years 1954-95. Statistics were analysed with Monson's computer program.

Results-Total mortality, when compared with the Canadian population, was significantly below expectation. Fewer deaths were found for circulatory disease, ischaemic heart disease, respiratory disease, neoplasms, digestive cancer, and accidents, poisonings, and violence. Among the 718 men in the group exposed to nickel, there were no deaths due to nasal cavity or paranasal sinus cancer. Fewer deaths were found for all causes, circulatory disease, ischaemic heart disease, neoplasms and digestive cancer. Lower death rates were observed than expected for respiratory malignancies and cancer of the bronchus and lung.

Conclusion-No association was found in this study between exposure to nickel concentrate or metallic nickel in the hydrometallurgical refining process and the subsequent development of respiratory cancer.

(Occup Environ Med 2001;58:711-715)
\end{abstract}

Keywords: epidemiology; nickel workers; mortality

In 1932, Bridge reported that workers at the Mond nickel refinery in Clydach, Wales were at increased risk of developing respiratory malignancies. ${ }^{1}$ Morgan noted that deaths from lung and nasal cancer at the Mond refinery occurred most often among workers employed as calciner furnace operators. ${ }^{2}$ Men in the calcining sheds were exposed to dusts emitted during the high temperature oxidation of nickelcopper sulfide. In 1984, Peto et al confirmed the increased risk of mortality from lung and nasal cancer at this Welsh nickel refinery. ${ }^{3}$

In 1950, L $\phi k e n$ reported an increased risk of lung cancer occurring among men employed in the roasting and shearing areas of a nickel
Main messages

- Pyrometallurgical and electrolytic nickel refining processes have been associated with increased risks of developing lung and nasal cancers among exposed workers.

- There is no evidence implicating the nonelectrolytic hydrometallurgical nickel refining process as a source of increased respiratory cancer.

- No association has been found between employment at the Sherritt hydrometallurgical nickel refinery in Fort Saskatchewan, Alberta and the subsequent development of respiratory cancer.

- There is no evidence that exposure to metallic nickel is associated with increased risks of lung and nasal cancer in human populations.

- The present study found no association between exposure to nickel concentrate or metallic nickel and the subsequent development of respiratory cancer.

Policy implications

- For decades, the many, diverse nickel compounds have been considered together for the purpose of establishing occupational exposure limits as well as carcinogenicity labeling.

- Clearly, metallic nickel should not be considered to be a human carcinogen.

- Consequently, regulatory agencies should establish occupational exposure limits and labelling standards separately for metallic nickel which reflects its noncarcinogenic status.

refinery in Kristiansand, Norway. ${ }^{4}$ Pedersen et al noted that electrolysis employees, as well as roaster and smelter workers at this Norwegian refinery had an increased risk of developing respiratory cancer. ${ }^{5}$ Workers in the electrolysis area were exposed primarily to nickel chloride and nickel sulfide, whereas roasting and smelting employees were exposed primarily to nickel-copper sulfide dust. ${ }^{6}$ In 1982, Magnus et al confirmed the increased risk of developing respiratory cancer at this Norwegian nickel refinery. ${ }^{7}$

The first study of cancer mortality at a Canadian nickel refinery was reported in 1959 by Sutherland. ${ }^{8} \mathrm{He}$ found that furnace and electrolysis workers at the Port Colborne, Ontario nickel plant had increased observed to 
expected ratios of deaths from lung and nasal cancer. $\mathrm{He}$ noted that calciner and sinter furnace employees were exposed to nickel monosulfide and nickel oxide dust and fumes, whereas electrolysis workers handled nickel salts, including nickel chloride and nickel sulphate. In 1967, Sutherland studied the Copper Cliff, Ontario nickel refinery and found that the risk of death due to lung cancer and nasal malignancies was increased in the sinter plant where nickel monosulfide was oxidised at high temperatures. ${ }^{9}$ In 1984, Roberts et al updated Sutherland's studies and confirmed the excess mortality from lung and nasal cancer at these Ontario pyrometallurgical nickel refineries. ${ }^{10}$

Unlike the roasting and calcining processes of pyrometallurgical nickel refineries, the hydrometallurgical process involves the application of chemicals under pressure in enclosed autoclaves to refine nickel. At the present time, evidence implicating the non-electrolytic hydrometallurgical nickel refining process as a source of increased respiratory cancer is lacking. In a series of studies by Egedahl et al, no association has been found between employment at the Sherritt hydrometallurgical nickel refinery in Fort Saskatchewan, Alberta and the subsequent development of respiratory cancer. ${ }^{11-13}$ The current investigation was undertaken to analyze the mortality experience of 1649 male Sherritt employees, including 718 nickel workers, between the years 1954 and 1995.

DESCRIPTION OF HYDROMETALLURGICAL NICKEL REFINING PROCESS

In 1954, Sherritt established hydrometallurgical nickel refining facilities at Fort Saskatchewan, Alberta. The primary raw material used at this operation from 1954 to 1976 was nickel-copper-cobalt sulfide ore mined and milled at the Sherritt Lynn Lake facility in Manitoba. At the Fort Saskatchewan nickel refinery, nickel ore concentrate is transferred from the concentrate sheds to the leach area where it is slurried in an aqueous ammoniaammonium sulphate solution and pumped into enclosed two stage pressure autoclaves. Anhydrous ammonia and air cause an exothermic leach reaction to occur with the metal components dissolving into solution as complex metal amines. Copper is removed as copper sulfide and precipitated by adding elemental sulphur and sulphur dioxide. Nickel is precipitated from solution as pure metallic powder by the addition of hydrogen in a pressure reduction autoclave. The nickel powder is washed free of sulphate solution, filtered, and dried in the metals recovery area. It is compacted into briquettes or metal strip in the rolling mill and metals fabrication area. Several special metal products are produced as composite powders and metal alloys, which are subsequently fabricated into finished metal components.

\section{Methods}

COHORT IDENTIFICATION

The primary objective of this study was to investigate the mortality experience at the
Sherritt hydrometallurgical nickel refinery and fertiliser complex of the male workers employed for at least 12 continuous months during the years 1954-78 and followed up for an additional 17 years to the end of 1995. A historical approach was used to compare the mortalities from various causes with those of the Canadian general population.

In 1978, information was assembled on all active employees, retired pensioners, and former workers employed for a minimum of one continuous 12 month period between January 1954 and December 1978 at the Fort Saskatchewan hydrometallurgical nickel refinery and fertiliser complex. As female employees comprised less than $10 \%$ of the cohort, women were not included in the statistical analysis. Data from personnel records were transferred to a summary data sheet for each employee and selected items were coded before data entry. This form detailed name, sex, address (last known address in the case of former employees), date of birth, social insurance number, date of starting employment, work history, and date of end of employment (in the case of former employees). Four separate work groups were established including a nickel cohort, maintenance group, fertiliser cohort, and office group. This paper presents the mortality experience of the total Sherritt cohort and the group exposed to nickel.

\section{CANADIAN MORTALITY DATA BASE}

The Canadian mortality data base was established in the late 1970s by Statistics Canada. It contains information regarding all deaths in Canada and is computerised with cause of death from 1950 onwards. Statistics Canada, in collaboration with the epidemiology unit of the National Cancer Institute of Canada, developed a now well established generalised iterative record linkage system to efficiently carry out the probabilistic matching of data files with the Canadian mortality data base. ${ }^{14}$ Among others, Shannon et al showed that this computerised record linkage with the Canadian mortality data base was very accurate. ${ }^{15}$

The Canadian mortality data base was used to search for deaths in the study cohort for the years 1954-95. For those who had died, copies of the death registrations were produced at Statistics Canada to standardise the coding of each death in the study cohort across the years to the ninth revision of the international classification of diseases (ICD-9).

\section{ASCERTAINMENT OF VITAL STATUS}

Verification of vital status is important when a mortality linkage is undertaken. An effort to determine whether people in the study cohort are dead or alive increases the reliability of the linkage made to the mortality file and decreases the number of "lost to follow up" cases. As this cohort contained a high percentage of valid social insurance numbers, Statistics Canada matched the Sherritt employee records to Canadian historical tax summary data for the years 1984-95 to help confirm vital status. All matches were verified at Statistics Canada. 
Table 1 Distribution of male Sherritt employees by age and year of entry into the cohort with person-years contribution to the study in parentheses

\begin{tabular}{lcccc}
\hline \multicolumn{5}{c}{ Year } \\
\cline { 2 - 5 } Age & $1954-9$ & $1960-9$ & $1970-9$ & Total \\
\hline$<20$ & $25(905.4)$ & $128(3265.9)$ & $215(4162.3)$ & $368(8333.6)$ \\
$20-29$ & $137(5110.4)$ & $352(8947.9)$ & $284(5544.6)$ & $773(19602.9)$ \\
$30-39$ & $132(4773.5)$ & $120(3197.9)$ & $92(1779.2)$ & $344(9750.6)$ \\
$40-49$ & $52(1694.7)$ & $47(1238.0)$ & $38(759.7)$ & $137(3692.4)$ \\
$50-59$ & $7(220.1)$ & $10(214.5)$ & $8(144.1)$ & $25(578.7)$ \\
$\geqslant 60$ & $1(17.2)$ & $1(20.3)$ & $0(0)$ & $2(37.5)$ \\
Total & $354(12721.3)$ & $658(16884.5)$ & $637(12389.9)$ & $1649(41995.7)$ \\
\hline
\end{tabular}

Table 2 Male Sherritt employees (1954-95) (observed and expected deaths (based on rates for Canada) and SMRs (95\% CI) by cause

\begin{tabular}{lrrrrr}
\hline Cause of death & Observed & Expected & SMR & 95\% CI \\
\hline All causes & 183 & 275.6 & 66 & 57 to & 77 \\
Neoplasms & 58 & 75.8 & 76 & 58 to & 99 \\
Digestive cancer & 12 & 21.3 & 56 & 29 to & 98 \\
Respiratory cancer & 23 & 27.0 & 85 & 54 to & 128 \\
Bronchus and lung & 20 & 25.3 & 79 & 48 to 122 \\
Pleura & 2 & 0.1 & 1135 & 127 to 4097 \\
Urinary cancer & 4 & 3.6 & 109 & 29 to & 278 \\
Genital cancer & 3 & 5.4 & 55 & 11 to & 161 \\
Nervous system cancer & 3 & 3.0 & 98 & 20 to 286 \\
Lymphoid cancer & 7 & 4.3 & 161 & 65 to 332 \\
Hodgkin's disease & 2 & 0.6 & 322 & 36 to 1162 \\
Non Hodgkin's lymphoma & 3 & 2.5 & 116 & 23 to & 339 \\
Multiple myeloma & 2 & 1.1 & 176 & 20 to & 636 \\
Leukaemias & 3 & 2.7 & 110 & 22 to & 322 \\
Ill defined neoplasms & 3 & 3.9 & 76 & 15 to & 223 \\
Circulatory disease & 70 & 106.5 & 66 & 51 to & 83 \\
Ischaemic heart disease & 51 & 75.6 & 67 & 50 to & 89 \\
Disease of arteries & 4 & 5.1 & 77 & 21 to & 198 \\
Aortic aneurysm & 4 & 2.8 & 141 & 38 to & 360 \\
Hypertensive disease & 2 & 1.1 & 171 & 19 to & 618 \\
Respiratory disease & 6 & 16.5 & 36 & 13 to & 79 \\
Chronic obstructive disease & 5 & 9.2 & 54 & 17 to & 126 \\
Digestive disease & 9 & 12.3 & 73 & 33 to & 139 \\
Genitourinary disease & 4 & 2.8 & 140 & 38 to & 357 \\
Accidents, poisonings, and violence & 26 & 39.2 & 66 & 43 to & 97 \\
Ill defined symptoms & 2 & 3.3 & 60 & 7 to & 218 \\
\hline
\end{tabular}

Table 3 Male nickel employees (1954-95) (observed and expected deaths (based on rates for Canada) and SMRs (95\% CI) by cause

\begin{tabular}{lccccc}
\hline Cause of death & Observed & Expected & \multicolumn{2}{c}{$S M R$} & \multicolumn{2}{c}{$95 \%$ CI } \\
\hline All causes & 59 & 103.2 & 57 & 43 to & 74 \\
Neoplasms & 13 & 27.4 & 47 & 25 to & 81 \\
Digestive cancer & 2 & 7.6 & 26 & 3 to & 94 \\
Respiratory cancer & 7 & 9.5 & 73 & 29 to & 151 \\
Bronchus and lung & 6 & 8.9 & 67 & 24 to & 146 \\
Lymphoid cancer & 3 & 1.6 & 184 & 37 to 537 \\
Multiple myeloma & 2 & 0.4 & 494 & 55 to 1782 \\
Circulatory disease & 22 & 38.3 & 57 & 36 to & 87 \\
Ischaemic heart disease & 16 & 27.0 & 59 & 34 to & 96 \\
Disease of arteries & 2 & 1.8 & 108 & 12 to & 391 \\
Aortic aneurysm & 2 & 1.0 & 200 & 22 to & 722 \\
Respiratory disease & 2 & 6.0 & 33 & 4 to & 119 \\
Digestive disease & 4 & 4.5 & 88 & 24 to & 224 \\
Accidents, poisonings, and violence & 12 & 17.0 & 70 & 36 to & 123 \\
Ill defined symptoms & 2 & 1.3 & 152 & 17 to & 549 \\
\hline
\end{tabular}

ANALYSIS

In 1974, Monson developed a computer program to perform 60 cause specific mortality analyses based on United States mortalities. ${ }^{16}$ This program has been modified and updated for use with Canadian mortality data. ${ }^{17}$ The cause specific analysis has been expanded to include 262 cause of death codes developed by the Laboratory Centre for Disease Control in Ottawa.

Standardised mortality ratios (SMRs) were calculated for these various causes of death. The SMR is the ratio of the observed number of deaths to the number of deaths that would have been expected in the general population multiplied by 100 . The SMRs were calculated for men by cause, age group, and calendar year of death. Person-years for the cohort members were accumulated within 5 year age and calendar year specific categories from the date they entered the cohort until their date of death or the end of the study, whichever came first. Mortalities for the Canadian general population for the years 1950-95 were used in the calculation of expected numbers of deaths. Ninety five per cent confidence intervals (95\% CIs) were calculated and significance was declared when the null value of 100 was not included in the interval.

\section{Results}

THE SHERRITT COHORT

The Sherritt cohort comprised 1649 men who accumulated 41995 person-years between 1954 and 1995. Table 1 shows a distribution of 1649 employees by age and onset of personyears experience. The average age at the start of employment was 27 years of age and the mean duration of follow up was 25 years. The average year of entry into the study was 1967 . Table 2 shows the observed and expected deaths by cause, SMRs, and 95\% CIs for the Sherritt cohort. There were 183 observed and 275.6 expected deaths, which resulted in an SMR of 66 and a $95 \%$ CI of 57 to 77 . This was a significant deficit of observed deaths in the study cohort. Significantly contributing to the deficit in all cause mortality were deaths in circulatory disease (SMR 66, 95\% CI 51 to 83), ischaemic heart disease (SMR 67, 95\% CI 50 to 89 ), respiratory disease (SMR 36, 95\% CI 13 to 79), neoplasms (SMR 76, 95\% CI 58 to 99), digestive cancer (SMR 56, 95\% CI 29 to 98), and accidents, poisonings, and violence (SMR 66, 95\% CI 43 to 97). One cause of death, cancer of the pleura (SMR 1,135, 95\% CI 127 to 4097 ) was significantly increased.

GROUP EXPOSED TO NICKEL

The group exposed to nickel comprised 718 men who accumulated 18237 person-years between 1954 and 1995. The average age of entry into the group was 25 years and the mean duration of follow up was 25 years. The average year of entry into the study group was 1967 .

For all causes, there were 59 observed and 103.2 expected deaths, which resulted in an SMR of 57 . The $95 \%$ CI was 43 to 74 . This was a significant deficit of observed deaths in the group exposed to nickel. Significantly contributing to the deficit in all cause mortality were deaths due to circulatory disease (SMR $57,95 \%$ CI 36 to 87 ), ischaemic heart disease (SMR 59, 95\% CI 34 to 96), neoplasms (SMR $47,95 \%$ CI 25 to 81 ), and digestive cancer (SMR 26, 95\% CI 3 to 94). Lower observed death rates were also found for respiratory malignancies and cancer of the bronchus and lung. No cause of death was significantly increased. Table 3 shows the observed and expected deaths by cause for the group exposed to nickel.

ASCERTAINMENT OF VITAL STATUS

A summary of the vital status determined by death linkage and follow up of live workers is presented in table 4 . Of the 1649 employees in 
Table 4 Summary of vital status determined by tax status and death linkage

\begin{tabular}{lcr}
\hline & Vital status on 31 \\
& December 1995 & $\%$ \\
\hline Alive & 1270 & 77.0 \\
Dead & 183 & 11.1 \\
Lost & 196 & 11.9 \\
Total & 1649 & 100.0 \\
\hline
\end{tabular}

the study, $1270(77 \%)$ were verified as alive, $183(11 \%)$ were dead, and $196(11 \%)$ were not found in the categories of dead, or people paying tax. People in the lost to follow up group would include a mixture of those who either had left Canada, did not file a tax return in 1995 , or lacked valid social insurance numbers. Those in the lost to follow up category were assumed to be alive for the statistical analysis of the data. This means that those people continued to accumulate person-years to the end of the study period of 31 December 1995 . Therefore, the results show a higher number of expected deaths for the population under study than if all such members were assumed to be dead.

INDUSTRIAL HYGIENE MONITORING RESULTS Industrial hygiene monitoring began at the Sherritt nickel refinery in 1977. At that time, five high volume area samples in the nickel concentrate sheds measured nickel dust concentrations ranging from 9 to $239 \mathrm{mg} / \mathrm{m}^{3}$ with a mean of $95 \mathrm{mg} / \mathrm{m}^{3}$. A total of 25 metallic nickel dust concentrations, obtained by high volume area monitoring, in the metals recovery area ranged from 0.3 to $49 \mathrm{mg} / \mathrm{m}^{3}$ with a mean of $4 \mathrm{mg} / \mathrm{m}^{3}$. Seven samples in the rolling mill and metals fabrication buildings, obtained by personal monitoring, showed metallic nickel dust concentrations ranging from 0.7 to 3 $\mathrm{mg} / \mathrm{m}^{3}$ with a mean of $2 \mathrm{mg} / \mathrm{m}^{3}$.

\section{Discussion}

THE SHERRITT COHORT

Among the 1649 male employees of Sherritt there was an overall mortality deficit which was significant. This finding of lower than expected mortality among employed populations has been partially attributed to the healthy worker effect. ${ }^{18} \mathrm{~A}$ significant finding of this study was 36 fewer observed deaths $(n=70)$ than expected $(n=106)$ due to circulatory disease. The main reason for the deficit was the significantly fewer number of deaths observed for ischaemic heart disease (51 observed, 75 expected). Statistically fewer observed than expected deaths were also found for neoplasms; digestive cancer; accidents, poisonings and violence; and respiratory disease. For malignancies of the bronchus and lung, fewer observed than expected deaths were also found (20 observed, 25 expected).

In the category of cancer of the pleura, there were two observed versus 0.1 expected deaths. These deaths due to mesothelioma of the pleura may be attributed to exposure to asbestos. Increased risk of developing mesothelioma has been shown among workers in asbestos mines, asbestos mills, and factories, as well as asbestos manufacture and installation. ${ }^{19}$
GROUP EXPOSED TO NICKEL

There was a significant overall mortality deficit for the 718 male nickel refinery employees. A central reason for this deficit was that 22 deaths were observed due to circulatory disease, 16 fewer than the expected 38. There were also significantly fewer deaths observed for ischaemic heart disease (16 observed, 27 expected), neoplasms (13 observed, 27 expected), and digestive cancer (two observed, seven expected).

This investigation focused on cancers of the respiratory system. In the present study, no deaths due to cancer of the nasal cavity or paranasal sinus were detected. In the group exposed to nickel, six deaths from lung cancer were found with 8.9 deaths expected.

\section{Conclusion}

Exposure to nickel subsulfide and nickel oxide in the pyrometallurgical nickel refining process has been associated with the development of nasal and lung cancers among nickel workers. At this time, evidence implicating metallic nickel as a respiratory carcinogen is lacking. Godbold and Tomkins found no association between exposure to metallic nickel at the Oak Ridge gaseous diffusion plant and subsequent development of lung cancer. ${ }^{20}$ Cragle et al reported on a follow up study of the employees of Oak Ridge gaseous diffusion plant which showed no evidence of increased mortality due to lung cancer among workers exposed to metallic nickel powder. ${ }^{21}$ Cox et al studied employees of a nickel alloy plant and found no relation between exposure to metallic nickel and the development of respiratory cancer. ${ }^{22}$

In 1990, the International Committee on Nickel Carcinogenesis in Man chaired by Sir Richard Doll reported its findings. ${ }^{23}$ This group concluded that "there was no evidence that metallic nickel was associated with increased lung and nasal cancer risks". Also in 1990, the International Agency for Research on Cancer concluded that there was "inadequate evidence in humans for the carcinogenicity of metallic nickel". ${ }^{24}$

The present study, which followed up the Sherritt group exposed to nickel from 1954 to 1995, found no deaths due to nasal cancer and six deaths from lung cancer when 8.9 deaths were expected (SMR 67). Consequently, no association was found at this time between exposure to nickel concentrate or metallic nickel and the subsequent development of respiratory cancer. The present study supports the findings of three previous investigations of the Sherritt group exposed to nickel. ${ }^{11-13}$

We thank the people at Sherritt International who assisted in this study, including Dr L Sheppard, Medical Consultant to Sherritt International. We are indebted to $\mathrm{M} \mathrm{E}$ Fair and $\mathrm{P}$ Lalonde of the Occupational and Environmental Health Research Section, Health Statistics Division at Statistics Canada. We thank the various provincial and territorial vital statistics registrars, as well as the Statistics Canada, Health Statistics Division for making the Canadin mortality data base tistics Division for making the Canadian mortality data base available for this study. In particular, we acknowledge the statistical analysis of the mortality data provided by Statistics Canada
using Monson's computer program.

1 Bridge JC. Annual report of the chief inspector of factories for the year 1932. London: The Stationery Office, 1933:103. 
2 Morgan JH. Some observations on the incidence of respiratory cancer in nickel workers. Br F Ind Med 1958;15:224 tory

3 Peto J, Cuckle H, Doll R, et al. Respiratory cancer mortality of Welsh nickel refinery workers. Nickel in the human environment. Lyon: International Agency for Research on Cancer, 1984:36-46. (IARC Sci Publ No 53.)

4 L $\phi k e n$ AC. Lung cancer in nickel workers. Tidsskr Nor Laegeforen 1950;70:376-8.

5 Pedersen E, Hogetveit AC, Andersen A. Cancer of respiratory organs among workers at a nickel refinery in Norway. Int $\mathcal{F}$ Cancer 1973;12:32-41.

6 Grimsrud TK, Berge SR, Resmann F, et al. Assessment of historical exposures in a nickel refinery in Norway. Scand $\mathcal{F}$ Work Environ Health 2000;26:338-45.

7 Magnus K, Andersen A, Hogetveit AC. Cancer of respiratory organs among workers at a nickel refinery in Norway. Int f Cancer 1982;30:681-5.

8 Sutherland RB. Summary of the report on respiratory cancer mortality at the International Nickel Company of Canada Limited, Port Colborne refinery. Toronto: Ontario DepartLimited, Port Colborne refinery. Toront
ment of Health, 1959. (Unpublished.)

9 Sutherland RB. Morbidity and mortality in selected occupations at the International Nickel Company of Canada Limited, Copper Cliff plant, 1950-1967. Toronto: Ontario Department of Health, 1967. (Unpublished.)

10 Roberts RS, Julian JA, Muir DCF, et al. Cancer mortality associated with high-temperature oxidation of nickel subsulphide. Nickel in the human environment. Lyon: International Agency for Research on Cancer, 1984:23-35. (IARC Sci Publ No 53.

11 Egedahl R, Rice E. Cancer incidence at a hydrometallurgical nickel refinery. Nickel in the human environment. Lyon: International Agency for Research on Cancer, 1984:47-55. (IARC Sci Publ No 53.)

12 Egedahl R, Coppock E, Homik R. Mortality experience at a hydrometallurgical nickel refinery in Fort Saskatchewan, Alberta between 1954 and 1984. F Soc Occup Med 1991;41:29-33.
13 Egedahl R, Carpenter M, Homik R. An update of an epidemiology study at a hydrometallurgical nickel refinery in Fort Saskatchewan, Alberta. Health Rep 1993;5:291-302.

14 Howe GR, Lindsay JP. A generalized iterative record linkage computer system for use in medical follow up studies. Comput Biomed Res 1981;14:327-40.

15 Shannon HS, Jamieson E, Walsh C, et al. Comparison of individual follow up and computerized record linkage using the Canadian mortality data base. Can $\mathcal{f}$ Public Health 1989;80:54-7.

16 Monson RR. Analysis of relative survival and proportional mortality. Comput Biomed Res 1974;7:325-32.

17 Raman S. Mortality analysis using Monson's computer program. Health Statistics Division. Ottawa: Statistics Canada, 1985. (Unpublished.)

18 Wen CP, Tsai SP. Anatomy of the healthy worker effect: a critique of summary statistics employed in occupational epidemiology. Scand $\mathcal{F}$ Work Environ Health 1982;8:48-52.

19 Selikoff IJ, Hammond EC, eds. Health hazards of asbestos exposure. Ann N Y Acad Sci 1979;330:1-811.

20 Godbold JH, Tomkins E. A long term mortality study of workers occupationally exposed to metallic nickel dust at the Oak Ridge gaseous diffusion plant. F Occup Med 1979; 21:799-806.

21 Cragle DL, Hollis DR, Newport TH, et al. A retrospective cohort mortality study among workers occupationally exposed to metallic nickel dust at the Oak Ridge gaseous diffusion plant. Nickel in the human environment. Lyon: International Agency for Research on Cancer, 1984:57-63. (IARC Sci Publ No 53.)

22 Cox JE, Doll R, Scott WA, et al. Mortality of nickel workers: experience of men working with metallic nickel. $\mathrm{Br} \mathcal{F}$ Ind Med 1981;38:235-9.

23 Doll R, Andersen A, Cooper WC, et al. Report of the international committee on nickel carcinogenesis in man. Scand 7 Work Environ Health 1990;16:1-82.

24 International Agency for Research on Cancer. Chromium, nickel and welding. IARC Monogr Eval Carcinog Risks Hum 1990;49:257-445.

\section{Answers to multiple choice questions on Review of the evidence for "Gulf War} syndrome" by $\mathrm{K}$ Ismail on pages 754-60.

(1) (a) false; (b) false; (c) true; (d) false; (e) false

(2) (a) false; (b) false; (c) false; (d) true; (e) false

(3) (a) false; (b) false; (c) false; (d) false; (e) true

(4) (a) false; (b) true; (c) false; (d) false; (e) false

(5) (a) false; (b) false; (c) true; $(d)$ false; (e) false 